\title{
Isolation and characterization of 15 microsatellite markers for the highly invasive box tree moth Cydalima perspectalis (Lepidoptera: Crambidae)
}

\author{
Audrey BRAS ${ }^{1}$, Laure SAUNÉ ${ }^{2}$, Alain ROQUeS ${ }^{1}$, Jérôme ROUSSElet $^{1}$ and Marie-Anne AUGer-ROZenberG ${ }^{1}$ \\ ${ }^{1}$ INRA, UR633 Unité de Recherche de Zoologie Forestière, 2163 Avenue de la Pomme de Pin, CS 40001 ARDON 45075 \\ ORLEANS Cedex 2, France; e-mails: audrey.bras@inra.fr, alain.roques@inra.fr, jerome.rousselet@inra.fr, \\ marie-anne.auger-rozenberg@inra.fr \\ 2 UMR1062 CBGP (INRA, CIRAD, IRD, Montpellier Supagro), INRA, 755 avenue du campus Agropolis, CS 30016, \\ 34988 Montferrier-sur-lez Cedex, France; e-mail: laure.saune@inra.fr
}

Key words. Lepidoptera, Crambidae, Cydalima perspectalis, microsatellites, invasive insect, genetic diversity

\begin{abstract}
In this study, we report the development of a set of 15 polymorphic microsatellite markers for the box tree moth, Cydalima perspectalis (Walker), a highly invasive insect in Europe causing significant damage to natural and ornamental Buxus trees. The markers were characterized for four distant populations in both its native (China, two populations) and invasive ranges (Czech Republic and Turkey, one population each). The number of alleles ranged from 2 to 12. No marker significantly deviated from the Hardy-Weinberg equilibrium for all the populations sampled. These microsatellite markers are promising tools for further studies on the invasive pathways and dispersal pattern of the box tree moth in Europe.
\end{abstract}

\section{INTRODUCTION}

The box tree moth, Cydalima perspectalis (Walker, 1859), is a pest insect native to East Asia. Its natural distribution includes China, Korea and Japan. The larvae feed on leaves and shoots of plants in the genus Buxus, which can result in their death (Wan et al., 2014). This invasive species was first recorded in 2007 in Germany (Krüger, 2008). Since then, it quickly spread across Europe causing significant damage in both urban areas planted with ornamental box trees and natural forest stands of Buxus sempervirens (Kenis et al., 2013). The trade in ornamental box plants between China and Europe is hypothesized as the invasion pathway for the box tree moth (Casteels et al., 2011) and the trade between European countries could account for its fast subsequent spread (Matošević, 2013). Elucidating invasion pathways of invasive species is essential for developing appropriate management programmes and preventing further introductions of Asian populations of $C$. perspectalis as well as those of other species that may use the same pathways (Estoup \& Guillemaud, 2010). Most of our knowledge about invasive pathways comes from historical and observational data, which may be incomplete and/or misleading. In this context, genetic markers have proved to be efficient tools for disentangling complex invasive pathways. The use of such markers facilitated the detection of a bridgehead effect in the invasion of the harlequin ladybird, Harmonia axyridis, in Europe (Lombaert et al., 2010). A similar approach used in the case of the invasive fruit fly Drosophila suzukii led to the suggestion that northeast China was the most probable source of the fly populations invasive in Europe while those invasive in western North America likely originated from southeast China and Hawaii (Fraimout et al., 2017). However, genetic markers are usually not available for recently-arrived invasive species and require development. Here, we report the development of a set of 15 polymorphic microsatellite markers for $C$. perspectalis and characterize the genetic variation for these loci in two native Asian populations and two populations invasive in Europe and Asia Minor.

\section{MATERIALS AND METHODS}

Total genomic DNA was isolated for the first step of the microsatellite loci screening, from one pooled sample of 15 individuals collected in both the native and invaded regions (Table 1). Both larvae and adult stages were dissected and DNA was extracted from thoracic muscles using the DNeasy ${ }^{\circledR}$ Blood and Tissue Kit (Qiagen, Hilden, Germany). Then, $1 \mu \mathrm{g}$ of the pooled DNA was used by GenoScreen (Lille, France) to develop microsatellite libraries using 454 GS-FLX Titanium pyrosequencing of enriched DNA libraries as described in Malausa et al. (2011). Briefly, total DNA was mechanically fragmented and enriched for $(\mathrm{TG})_{10},(\mathrm{TC})_{10},(\mathrm{AAC})_{8},(\mathrm{AAG})_{8},(\mathrm{AGG})_{8},(\mathrm{ACG})_{8},(\mathrm{ACAT})_{6}$ and $(\mathrm{ACTC})_{6}$ repeat motifs. Enriched fragments were subsequently amplified. PCR products were purified, quantified and one GsFLX library was then created following the manufacturer's protocols and sequenced on a GsFLX PTP. The bioinformatics program QDD (Meglécz et al., 2010) was used to analyze sequences. QDD was used to conduct all bioinformatic steps from raw sequences until PCR primers were obtained. Briefly, adapters/vectors were removed and sequences with microsatellites were identified. Sequences with redundancy and/or enriched with possible mobile element associations were detected through an "all against all" BLAST in order to remove microsatellite sequences that were 
Table 1. Description of Cydalima perspectalis samples used in the different steps in the development of the microsatellites.

\begin{tabular}{|c|c|c|c|c|c|c|c|c|c|}
\hline Area & Country & Locality & GPS coordinates & $\begin{array}{l}\text { Year of } \\
\text { collection }\end{array}$ & $\begin{array}{l}\text { Insect } \\
\text { stage }\end{array}$ & $\begin{array}{c}\text { Insect } \\
\text { sex }\end{array}$ & $\begin{array}{c}454 \\
\text { sequencing }\end{array}$ & $\begin{array}{c}\text { PCR } \\
\text { amplification } \\
\text { tests }^{2}\end{array}$ & $\begin{array}{l}\text { Population } \\
\text { polymorphism } \\
\text { analysis }^{3}\end{array}$ \\
\hline \multirow[t]{9}{*}{ Invaded } & Belgium & Lochristi & $51^{\circ} 5^{\prime} 37^{\prime \prime N} ; 3^{\circ} 50^{\prime} 15^{\prime \prime E}$ & 2015 & Adult & $\mathrm{F}$ & 1 & - & - \\
\hline & Czech Republic & Brno & $49^{\circ} 12^{\prime} 44^{\prime \prime} \mathrm{N} ; 16^{\circ} 36^{\prime} 53^{\prime \prime} \mathrm{E}$ & 2016 & Larvae & - & - & - & 30 \\
\hline & France & Barjouville & $48^{\circ} 24^{\prime} 38^{\prime \prime N} ; 1^{\circ} 28^{\prime} 39^{\prime \prime} \mathrm{E}$ & 2015 & Adult & M & 1 & - & - \\
\hline & France & Orléans & $47^{\circ} 54^{\prime} 21^{\prime \prime N} ; 1^{\circ} 57^{\prime} 53^{\prime \prime} \mathrm{E}$ & 2015 & Adult & M & 1 & 2 & - \\
\hline & France & Lagnes & $43^{\circ} 53^{\prime} 38^{\prime \prime N} ; 5^{\circ} 6^{\prime} 31^{\prime \prime E}$ & 2015 & Adult & M & 1 & 2 & - \\
\hline & Georgia & Zugdidi & $42^{\circ} 30^{\prime} 46^{\prime \prime} \mathrm{N} ; 41^{\circ} 52^{\prime} 26^{\prime \prime} \mathrm{E}$ & 2015 & Larvae & - & 1 & - & - \\
\hline & Germany & Lorsch & $49^{\circ} 38^{\prime} 58^{\prime \prime N}$; $8^{\circ} 33^{\prime} 54^{\prime \prime} \mathrm{E}$ & 2014 & Adult & $\mathrm{F}$ & 1 & - & - \\
\hline & Serbia & Belgrade & $44^{\circ} 47^{\prime} 18^{\prime \prime N} \mathrm{~N} ; 20^{\circ} 27^{\prime} 38^{\prime \prime} \mathrm{E}$ & 2015 & Larvae & - & 1 & - & - \\
\hline & Turkey & Istanbul & $41^{\circ} 0^{\prime} 40^{\prime \prime} \mathrm{N} ; 28^{\circ} 59^{\prime} 0^{\prime \prime} \mathrm{E}$ & 2015 & Larvae & - & - & - & 30 \\
\hline \multirow[t]{10}{*}{ Native } & China & Lu'an & NA & 2015 & Adult & M & 1 & 1 & - \\
\hline & China & Jinan & $36^{\circ} 38^{\prime} 27^{\prime \prime N} ; 117^{\circ} 7^{\prime} 12^{\prime \prime} \mathrm{E}$ & 2012 & Adult & $\mathrm{F}$ & 1 & - & - \\
\hline & China & Linyi & NA & 2015 & Adult & M & 1 & - & - \\
\hline & China & Linyi & NA & 2015 & Adult & M & 1 & 1 & - \\
\hline & China & Taian & $36^{\circ} 11^{\prime} 18^{\prime \prime N} ; 117^{\circ} 5^{\prime} 14^{\prime \prime E}$ & 2012 & Adult & M & 1 & - & - \\
\hline & China & Lijiang & $26^{\circ} 54^{\prime} 22^{\prime \prime} \mathrm{N} ; 100^{\circ} 13^{\prime} 28^{\prime \prime} \mathrm{E}$ & 2016 & Larvae & - & - & - & 29 \\
\hline & China & Fuyang & $30^{\circ} 0^{\prime} 12^{\prime \prime N}$; $119^{\circ} 47^{\prime} 59^{\prime \prime} \mathrm{E}$ & 2015 & Larvae & - & 1 & 1 & 23 \\
\hline & China & Fuyang & $30^{\circ} 0^{\prime} 12^{\prime \prime} \mathrm{N} ; 119^{\circ} 47^{\prime} 59^{\prime \prime} \mathrm{E}$ & 2015-2016 & Adult & $\mathrm{M} / \mathrm{F}$ & - & - & 7 \\
\hline & China & Hangzhou & $30^{\circ} 15^{\prime} 35^{\prime \prime} \mathrm{N} ; 120^{\circ} 9^{\prime} 15^{\prime \prime} \mathrm{E}$ & 2012 & Adult & $\mathrm{F}$ & 1 & - & - \\
\hline & South Korea & Seoul & $37^{\circ} 26^{\prime} 3^{\prime \prime N}$; $126^{\circ} 58^{\prime} 43^{\prime \prime E}$ & 2012 & Larvae & - & 1 & 1 & - \\
\hline
\end{tabular}

Information for each sample includes insect stage; Insect sex when known; ${ }^{1}$ Number of individuals $(n=15)$ used for biotin-enrichment and 454 pyrosequencing steps; ${ }^{2}$ Number of individuals $(n=8)$ used to test PCR amplification on an agarose gel of the 40 primer set selected; ${ }^{3}$ Number of individuals used for screening for polymorphism, testing HW equilibrium, LD and null allele frequency.

unlikely to provide a clear amplification pattern. Then, a selection of sequences with target microsatellites were used to design primer sets using BLAST, ClustalW and Primer3 programmes. Among 4,243 sequences containing a microsatellite motif, 336 primer sets were designed using this software.
A total of 40 candidate primer sets with both an expected size between $90-110 \mathrm{bp}, 150-200 \mathrm{bp}$ or 250-300 bp and at least 7 or more repetitions of the microsatellite motif were assessed for amplification performance in 8 individuals of $C$. perspectalis from native and invaded ranges. A total of 15 primer sets were

Table 2. Description of the fifteen microsatellite loci developed for Cydalima perspectalis.

\begin{tabular}{|c|c|c|c|c|c|c|c|c|}
\hline Locus & Primer sequence $\left(5^{\prime}-3^{\prime}\right)$ & GenBank & Repeat motif & Set & Ta & Dye & $\mathrm{Na}$ & Allele size range \\
\hline BTM01 & $\begin{array}{l}\text { F: AGTTGTGGAGATCCATGCAA } \\
\text { R: ATTTAATCACTGCGCGTTCA }\end{array}$ & MH151896 & $(G A)_{8}$ & 1 & 58 & 6-FAM & 2 & 83-85 \\
\hline BTM06 & $\begin{array}{l}\text { F: GTCCAGGTGGCTTTGTGTTT } \\
\text { R: TCAAATAAAATTCGTACCGCAA }\end{array}$ & MH151897 & $(A G)_{8}$ & 1 & 58 & NED & 4 & $87-93$ \\
\hline BTM09 & $\begin{array}{l}\text { F: CATGAGCGGGTCTTAGCATT } \\
\text { R: TGAAAGGCCGTATTACCGTT }\end{array}$ & MH151898 & $(\mathrm{AG})_{7}$ & 2 & 59 & 6-FAM & 10 & 89-111 \\
\hline BTM13 & $\begin{array}{l}\text { F: AACCTTATGACGGATCCAAAA } \\
\text { R: GGGGACCTTGCTTCTCTACC }\end{array}$ & MH151899 & $(G A)_{8}$ & 2 & 59 & NED & 5 & $93-113$ \\
\hline BTM15 & $\begin{array}{l}\text { F: CTAGGCCAGATATGCCGAAA } \\
\text { R: CGCACCGTGTACTATTTGCT }\end{array}$ & MH151900 & $(\mathrm{GA})_{7}$ & 2 & 59 & VIC & 4 & $146-152$ \\
\hline BTM16 & $\begin{array}{l}\text { F: CATTATACGAGCAGGCGCAG } \\
\text { R: AGAACGTTAGGCAGATGTTCA }\end{array}$ & MH151901 & $(\mathrm{AT})_{7}$ & 3 & 61 & 6-FAM & 9 & $143-159$ \\
\hline BTM20 & $\begin{array}{c}\text { F: TTTGATTAGTTTAGAATTGGTCAGTTT } \\
\text { R: CCGTCTCAGCGTTTTACACA }\end{array}$ & MH151902 & $(\mathrm{GT})_{10}$ & 1 & 58 & VIC & 10 & $153-175$ \\
\hline BTM22 & $\begin{array}{l}\text { F: CCTGTGTAAACGATACCCCTG } \\
\text { R: CCGTTTACTCCCATTAGCGA }\end{array}$ & MH151903 & $(\mathrm{TC})_{7}$ & 2 & 59 & PET & 3 & 164-167 \\
\hline BTM23 & $\begin{array}{l}\text { F: AATGGGAATTCGTCGTCACT } \\
\text { R: AACACCAACCACAACAGCAA }\end{array}$ & MH151904 & $(\mathrm{GTT})_{13}$ & 1 & 58 & 6-FAM & 12 & 150-195 \\
\hline BTM27 & $\begin{array}{l}\text { F: AACCTCTAGAAACCGCTCAGT } \\
\text { R: GTTTGAGCGGAGCTTGTACC }\end{array}$ & MH151905 & $(\mathrm{TG})_{11}$ & 1 & 58 & NED & 7 & $167-179$ \\
\hline BTM28 & $\begin{array}{l}\text { F: CGGGGATTATAGGCGTGAT } \\
\text { R: CCCTTAATGCATCTCGAAACA }\end{array}$ & MH151906 & $(\text { TATG })_{13}$ & 3 & 61 & VIC & 4 & $151-179$ \\
\hline BTM34 & $\begin{array}{l}\text { F: TCCCCATATGTATTTCATTTTGTTT } \\
\text { R: CATTTGGAAATTTCATTACGCA }\end{array}$ & MH151907 & $(\mathrm{TC})_{7}$ & 2 & 59 & 6-FAM & 4 & $240-248$ \\
\hline BTM35 & $\begin{array}{l}\text { F: GACCCTTATGCCCACTGCTA } \\
\text { R: ACTGCCGATTATCTGCCTCA }\end{array}$ & MH151908 & $(A G)_{9}$ & 2 & 59 & NED & 4 & 234-260 \\
\hline ВTM36 & $\begin{array}{l}\text { F: TAAACTCCCACGCTAATGGG } \\
\text { R: TGGCAAAGGTCCATGACATA }\end{array}$ & MH151909 & $(A C)_{14}$ & 1 & 58 & PET & 9 & $257-273$ \\
\hline BTM40 & $\begin{array}{l}\text { F: TCAGCGGTTTAAAGTTCCAG } \\
\text { R: CTCCACAACCGACTTAACCG }\end{array}$ & MH151910 & $(A G T)_{8}$ & 2 & 59 & VIC & 10 & 263-329 \\
\hline
\end{tabular}

Information presented includes primer sequence, GenBank accession number, Repeat motif, Multiplex PCR set, Annealing temperatures in ${ }^{\circ} \mathrm{C}(\mathrm{Ta})$, Fluorescent dye colour, Number of observed alleles ( $\left.\mathrm{Na}\right)$, and Allele size range. 
Table 3. Polymorphism characterization of 15 microsatellite loci of two native populations of Cydalima perspectalis (Fuyang \& Lijiang, China) and two invasive populations (Brno, Czech Republic and Istanbul, Turkey).

\begin{tabular}{|c|c|c|c|c|c|c|c|c|c|c|c|c|c|c|c|c|c|c|c|c|}
\hline \multirow{2}{*}{ Locus } & \multicolumn{5}{|c|}{ Fuyang $(n=30)$} & \multicolumn{5}{|c|}{ Lijiang $(n=29)$} & \multicolumn{5}{|c|}{ Brno $(n=30)$} & \multicolumn{5}{|c|}{ Istanbul $(\mathrm{n}=30)$} \\
\hline & Ja & $\mathrm{Ho}$ & $\mathrm{He}$ & $P$-value & $f$ & $\mathrm{Na}$ & $\mathrm{Ho}$ & $\mathrm{He}$ & $P$-value & $f$ & $\mathrm{Na}$ & $\mathrm{Ho}$ & $\mathrm{He}$ & $P$-value & $f$ & $\mathrm{Na}$ & Ho & $\mathrm{He}$ & $P$-value & $f$ \\
\hline & & & & & & & - & - & - & & & & - & - & & & & & & \\
\hline & & & & & & 3 & & & & & 2 & & & & & & & & & \\
\hline & 10 & & & & & & & & & & & & & & & & & & & \\
\hline & & & & & & & & & & & & & & & & & & & & \\
\hline & & & & & & & & & & & & & & & & & & & & \\
\hline & & & & & & & & & & & & & & & & & & & & \\
\hline & & & & & & & & & & & & & & & & & & & & \\
\hline & & & & & & & & & & & & & & & & & & 67 & & \\
\hline & & & & & & & & & & & & & & & & & & & & 0 \\
\hline & 7 & & & & & & & & & & & & & & & & & 68 & & .00 \\
\hline & 4 & 0.200 & 0.273 & 016 & & 2 & & & & & 2 & 67 & 0.066 & 000 & & & & .097 & .000 & .00 \\
\hline & 1 & - & - & - & & 4 & 0.286 & 77 & & & 1 & - & - & - & & & - & - & - & 0.00 \\
\hline & 3 & 0.633 & 0.508 & 325 & 0.000 & 3 & & & & & 1 & - & - & - & & 2 & & 0.413 & 1.000 & 0.00 \\
\hline & 7 & 0.467 & 678 & & & 6 & & 735 & & & 5 & 0.700 & 0746 & & & 4 & & 43 & 0.814 & 0.00 \\
\hline IIV140 & 0 & 0.800 & 0.138 & .3599 & 0.000 & & .539 & 0.172 & (.0156 & $0.1 \angle 8$ & 4 & 0.019 & $0.46 /$ & $0.1<49$ & 0.084 & & $0.56 \%$ & 0.015 & 0.0940 & 0.0 \\
\hline
\end{tabular}

Information for each population presented includes Number of observed alleles (Na); Observed heterozygosity (Ho); Expected heterozygosity $(\mathrm{He})$; and Null allele frequency $(f)$. $P$-value of the deviation from Hardy-Weinberg proportion (HW) provided (without Bonferroni correction).

selected and microsatellite forward primers were labelled using fluorescent dyes NED, 6-FAM, PET and VIC (Applied Biosystem, Renfrewshire, UK) to allow for PCR product multiplexing (Table 2). PCR amplifications were done in a total volume of 10 $\mu \mathrm{L}$ using the Multiplex PCR Kit (Qiagen $\left.{ }^{\circledR}\right)$. Thermocycling was carried out in a Veriti ${ }^{\circledR} 96$ well fast thermal cycler (Applied Biosystems $\left.{ }^{\circledR}\right)$ and the following protocol: initial denaturation step of $94^{\circ} \mathrm{C}$ for $15 \mathrm{~min}$ followed by 40 amplification cycles of $94^{\circ} \mathrm{C}$ for $30 \mathrm{~s}, 58-61^{\circ} \mathrm{C}$ for $45 \mathrm{~s}, 72^{\circ} \mathrm{C}$ for $30 \mathrm{~s}$ and a final elongation step at $72^{\circ} \mathrm{C}$ for $30 \mathrm{~min}$. Fragments were run on an ABI Prism 3500 sequencer. Raw data for each fluorescent DNA product were visualized using GeneMapper v. 4.1 (Applied Biosystems ${ }^{\circledR}$ ) and allele sizes were scored against an internal GenScan-600 LIZ® Size Standard (Applied Biosystem ${ }^{\circledR}$ ).

The fifteen microsatellite markers were characterized using 4 populations (29-30 individuals each): 2 populations sampled in the two distant parts of the native range of the box tree moth in China (southwestern China - Lijiang and southeastern China Fuyang) and 2 populations sampled in two distant parts in the area presently invaded in Europe and Asia Minor (Czech Republic - Brno and Turkey - Istanbul; Table 1). Observed and expected heterozygosity, deviation from Hardy-Weinberg proportion (HW) and Linkage Disequilibrium (LD) were calculated using Arlequin v. 3.5 (Excoffier \& Lischer, 2010), and the conservative correction of Bonferroni was not applied. The presence of null alleles was checked using FreeNA (Chapuis \& Estoup, 2007).

\section{RESULTS AND DISCUSSION}

The total number of alleles ranged from 2 to 12 (Table 2). Two loci (BTM01 and BTM34) were found to be monomorphic in the invading populations studied (Table 3 ) whereas in the native populations BTM01 was monomorphic for those at Lijiang and BTM34 monomorphic for those at Fuyang. Observed and expected heterozygosity ranged from 0.000 to 0.900 and 0.066 to 0.858 , respectively. Global expected heterozygosity $\mathrm{He}$ was 0.518 at Fuyang, 0.519 at Lijiang, 0.386 at Brno and 0.441 at Istanbul. Significant departures from HW proportion were detected for different markers in the four populations sampled. Nevertheless, no primer pair significantly deviated from HW in the four populations. LD results showed that only one pair (BTM13-BTM15) was linked in the populations from Fuyang, Brno and Istanbul. The other microsatellite markers did not show significant LD in the four populations. Null allele frequency ranged from 0.000 to 0.237 . The null allele frequency of six markers was larger than $15 \%$ in at least one population (BTM01, BTM06, BTM13, BTM15, BTM16 and BTM22). Presence of null alleles and HW disequilibrium for some loci was not surprising since it has also been observed in microsatellite sets developed for other lepidopteran species (Kim et al., 2008; Sinama et al., 2011; Lebigre et al., 2015). Moreover, a part of the HW disequilibrium recorded for BTM01, BTM06, BTM13, BTM15, BTM16 and BTM22 loci in no more than three of the four populations studied could be explained by the presence of null alleles, sex-linked loci or population demography history.

For further genetic analyses on C. perspectalis, sex-linked disequilibrium still needs to be investigated since we did not have enough adults in the genotyped populations to test for it. In addition, BTM01 loci characteristics will need to be tested in other populations to determine the utility of this marker because this primer was found to be monomorphic in three of the four populations studied, and significantly deviated from HWE and there was a high null allele frequency in the Fuyang population. Moreover, $\mathrm{LD}$, especially in the native area, needs to be more investigated for the BTM13 and BTM15 markers. Nevertheless, these first microsatellite markers available for $C$. perspectalis are promising molecular tools for further analysing the invasion routes of this highly invasive pest and disentangling the dispersal patterns that could explain its very fast spread in Europe and the Caucasus region.

ACKNOWLEDGEMENTS. We would like to acknowledge C. Kerdelhué for her advices and H. Li, M. Kenis, A. Herz, E. Morel, L. Van Remoortere and M. Glavendekić for help with collecting the insects. This research was supported by the project INCA ("Invasion fulgurante de la pyrale du buis Cydalima perspectalis en Région Centre Val de Loire") financed by the French Region Centre Val-de-Loire (project INCA APR IR 2015-0009673). We also would like to acknowledge two anonymous reviewers for their comments on the manuscript and F. Marec for his helpful editorial comments.

\section{REFERENCES}

Casteels H., Witters J., Vandierendonck S., Van Remoortere L. \& Goossens F. 2011: First report of Cydalima perspecta- 
lis (Lepidoptera: Crambidae) in Belgium. In Vandekerhove B. (ed.): Proceedings of the 63rd International Symposium on Crop Protection, Gent, May 24, 2011. Vol. 2. - Comm. Appl. Biol. Sci. (Ghent) 76: 151-155.

Chapuis M.-P. \& Estoup A. 2007: Microsatellite null alleles and estimation of population differentiation. - Mol. Biol. Evol. 24 621-631.

Estoup A. \& Guillemaud T. 2010: Reconstructing routes of invasion using genetic data: why, how and so what? - Mol. Ecol. 19: 4113-4130.

EXCOFFIER L. \& Lischer H.E.L. 2010: Arlequin suite ver 3.5: A new series of programs to perform population genetics analyses under Linux and Windows. - Mol. Ecol. Resour. 10: 564-567.

Fraimout A., Debat V., Fellous S., Hufbauer R.A., Foucaud J., Pudlo P., Marin J.-M., Price D.K., Cattel J., Chen X. et al. 2017: Deciphering the routes of invasion of Drosophila suzukii by means of ABC random forest. - Mol. Biol. Evol. 34: 980-996.

Kenis M., Nacambo S., Leuthardt F., Di Domenico F. \& Haye T. 2013: The box tree moth Cydalima perspectalis, in Europe: Horticultural pest or environmental disaster? - Aliens 33: $38-41$.

Kim K.S., Coates B.S., Hellmich R.L., Sumerford D.V. \& SAPPINGTON T.W. 2008: Isolation and characterization of microsatellite loci from the European corn borer, Ostrinia nubilalis (Hübner) (Insecta: Lepidoptera: Crambidae). - Mol. Ecol. Resour. 8: 409-411.

KRÜGER E.O. 2008: Glyphodes perspectalis (Walker, 1859) - new for the European fauna (Lepidoptera: Crambidae). - Entomol. Z. Mit. Insekten-Börse 118: 81-83 [in German with English abstr.].
Lebigre C., Turlure C. \& Schtickzelle N. 2015: Characterisation of sixteen additional polymorphic microsatellite loci for the spreading but locally rare European butterfly, Brenthis ino (Lepidoptera: Nymphalidae). - Eur. J. Entomol. 112: 389392.

Lombaert E., Guillemaud T., Cornuet J.-M., Malausa T., Facon B. \& Estoup A. 2010: Bridgehead effect in the worldwide invasion of the biocontrol harlequin ladybird. - PLOS ONE 5: e9743, 7 pp.

Malausa T., Gilles A., Meglécz E., Blanquart H., Duthoy S., Costedoat C., Dubut V., Pech N., Castagnone-Sereno P., DéLye C. ET AL. 2011: High-throughput microsatellite isolation through 454 GS-FLX Titanium pyrosequencing of enriched DNA libraries. - Mol. Ecol. Resour. 11: 638-644.

MatošEvić D. 2013: Box tree moth (Cydalima perspectalis, Lepidoptera; Crambidae), new invasive insect pest in Croatia. SEEFOR South-East Eur. For. 4: 89-94.

Meglécz E., Costedoat C., Dubut V., Gilles A., Malausa T., Pech N. \& Martin J.-F. 2010: QDD: a user-friendly program to select microsatellite markers and design primers from large sequencing projects. - Bioinformatics 26: 403-404.

Sinama M., Dubut V., Costedoat C., Gilles A., Junker M., Malausa T., Martin J.-F., Neve G., Pech N., Schmitt T. et AL. 2011: Challenges of microsatellite development in Lepidoptera: Euphydryas aurinia (Nymphalidae) as a case study. Eur. J. Entomol. 108: 261-266.

Wan H., Haye T., Kenis M., Nacambo S., Xu H., Zhang F. \& Li H. 2014: Biology and natural enemies of Cydalima perspectalis in Asia: Is there biological control potential in Europe? - J. Appl. Entomol. 138: 14-26.

Received February 2, 2018; revised and accepted May 16, 2018 Published online June 6, 2018 